\title{
Descrição de uma espécie nova de Centris Fabricius da Bahia, Brasil (Hymenoptera, Apoidea) ${ }^{1}$
}

\author{
Jesus Santiago Moure ${ }^{2}$ \\ Favízia Freitas de Oliveira ${ }^{3}$ \\ Blandina Felipe Viana ${ }^{4}$
}

Abstract. Description of a new species of Centris Fabricius from Bahia, Brazil (Hymenoptera, Apoidea). Centris (Centris)
pulchra sp. nov. is described and illustrated. The specimens were collected in a restricted area of coastal sand dunes with
"restinga" vegetation in northeast of Brazil, near Salvador-BA.

Keywords. Apoidea; Centris; Hymenoptera; Northeast of Brazil; restinga.

\section{INTRODUÇÃO}

Iniciados por SAKagami et al. (1967), os levantamentos sistemáticos de abelhas e flora associada vêm sendo realizados em várias localidades e em diferentes ecossistemas ao longo de todo o território nacional (PINHEIRO-MACHADO et al. 2002). Embora esses estudos venham contribuindo para ampliar o conhecimento da nossa apifauna, esta continua ainda relativamente desconhecida devido, principalmente, aos impedimentos taxonômicos, adicionado ao fato de que, em cada novo levantamento, é também descoberto grande número de espécies novas para ciência. De acordo com SiLVeIRA et al. (2002), das 3.187 morfo-espécies reconhecidas em 46 levantamentos, apenas $26 \%$ foram seguramente identificadas, sendo que $6 \%$ foram representados por espécies novas.

Desse modo, descrições detalhadas das espécies novas são muito relevantes, pois contribuem para o reconhecimento correto da nossa apifauna, além de servirem como subsídios para a elaboração de chaves de identificação e como ferramenta adicional para estudos que pretendam esclarecer as relações filogenéticas entre grupos de abelhas.

Em estudo recente realizado por um dos autores do presente artigo (B. F. Viana), em vegetação de dunas litorâneas em Salvador-BA, Brasil, várias espécies novas de abelhas foram descobertas, as quais representaram 20,4\% das espécies coletadas. Dentre essas espécies, apenas uma pertencente a Centris (Centris) (Anthophoridae sensu Moure) será descrita no presente trabalho, e as demais em trabalhos futuros.

\section{MATERIALEMÉTODOS}

Os espécimes foram coletados quando em visita às flores, no período de janeiro a dezembro de 1996. A área estudada foi um fragmento de dunas litorâneas ( 8,2 hectares), situado na Área de Proteção Ambiental das Lagoas e Dunas de Abaeté (Salvador, Bahia, Brasil, 12 ${ }^{\circ} 56^{\prime} \mathrm{S} / 38^{\circ} 21^{\prime} \mathrm{W}$ ). Essas dunas são cobertas por vegetação do tipo restinga, formando manchas compostas por espécies arbóreas e arbustivas, cuja altura geralmente não ultrapassa $3 \mathrm{~m}$, podendo ocorrer algumas plantas emergentes.

Para as descrições, as mensurações foram feitas com microscópio estereoscópico Leica MZ12, equipado com ocular micrométrica; as medidas são dadas em milímetros. No item "Material-tipo", os números entre parênteses referem-se aos códigos das plantas, registrados nas etiquetas das abelhas, os quais são utilizados para identificação das mesmas no banco de dados do Laboratório de Biologia e Ecologia de Abelhas (LABEA), do Instituto de Biologia da Universidade Federal da

1. Contribuição ${ }^{\circ} 1431$ do Departamento de Zoologia, Universidade Federal do Paraná.

2. Departamento de Zoologia, Universidade Federal do Paraná. Caixa Postal 19020, 81531-980 Curitiba-PR, Brasil. Endereço eletrônico: jsmoure@bol.com.br; Bolsista do CNPq.

3. Departamento de Zoologia, Universidade Federal do Paraná. Endereço eletrônico: favos@ bol.com.br - Bolsista da CAPES.

4. Laboratório de Biologia e Ecologia de Abelhas (LABEA), Departamento de Zoologia, Instituto de Biologia, Universidade Federal da Bahia. Rua Barão de Geremoabo s/n, Campus Universitário de Ondina, 40170-110 Salvador-BA, Brasil. Endereço eletrônico: blandefv@ufba.br Bolsista do CNPq. 
Bahia (UFBA).

\section{Centris (Centris) pulchra sp. nov.}

(Figs. 1-6)

Holótipo fêmea. Comprimento total aproximado 13,9; comprimento da asa anterior 7,9; largura máxima da cabeça 4,7; largura do metassoma na altura de T2 4,7.

Cor. O corpo em geral castanho-enegrecido, exceto: pernas e metassoma ferrugíneos, sendo o $5^{\circ}$ tergo acastanhado; ricos desenhos amarelos vivos na face: clípeo, exceto por duas estrias estreitas castanho-escuras, divergentes, localizadas no terço superior, e separadas em cima por uma distância equivalente ao diâmetro do ocelo (Fig. 1); labro; área malar; 2/3 basais das mandíbulas; um triângulo curto e largo na região supraclipeal; estrias paroculares alargadas inferiormente, com maior largura ao nível das fóveas tentoriais, estreitando-se gradualmente para cima, terminando acima da tangente alveolar superior, a uma distancia de um e meio diâmetro do alvéolo; larga estria na margem látero-posterior do escapo. Uma pequena mancha amarela na base das tíbias 1 e 2, sendo mais desenvolvida dentro da placa basitibial das tíbias 3 (Fig. 2); tégulas pardoferrugíneo-claras; membrana alar levemente amarelada, apresentando uma pequena estria acastanhada no terço basal da célula marginal, uma veia muito fina em arco, transversal, no terço apical da primeira célula submarginal (partindo do prestigma) e pequenas áreas escurecidas, as quais são resultantes da presença de micro-cerdas castanhas, mais nítidas na célula radial e na primeira célula submarginal; venação pardo negra, ligeiramente amarelada nos $2 / 3$ distais do pterostígma e na base da asa; reflexos azul-metálicos do $2^{\circ}$ ao $5^{\circ}$ tergos, mais nítidos no $5^{\circ}$.

Pilosidade. No geral amarelado-pálida (Fig. 3), com a extremidade dos pêlos fulva na parte dorsal do mesossoma, na parte superior dos mesepisternos e no vértice, passando a esbranquiçada na parte inferior da face e da gena, na porção ventral dos mesepisternos e na base do metassoma; fêmures e tíbias com pilosidade esbranquiçada, porém mais longa nos fêmures anteriores; nos tarsos anteriores parda e, nos médios e posteriores, acastanhada; faixas estreitas de cerdas curtíssimas, esbranquiçadas, marginando o bordo posterior dos tergos 2 a 4, alargadas para os lados e estreitadas no meio, não interrompidas. No $5^{\circ}$ tergo uma franja apical de cerdas longas, acastanhadas, mais escuras na base da placa pigidial. A maior parte da área basal dos tergos 2 a 4 preto-cerdosa; no tergo 1 as cerdas pretas apenas no meio, por baixo dos pêlos esbranquiçados; franjas abdominais apicais densas do $2^{\circ}$ ao $5^{\circ}$ esternos, com os pêlos da faixa central diferenciados: castanhos, um pouco mais longos, espessos e densamente ramificados; no $5^{\circ}$ esterno, possuem uma haste relativamente longa ( $2 / 3$ do comprimento do pêlo) e são encurvados.

Pontuação. Densa e de tamanho moderado: na fronte, o espaçamento de $1 / 2$ diâmetro de ponto com os intervalos careniformes, um pouco mais lisa na supraclipeal, muito irregular no disco do clípeo e mais evidente nos declives laterais e, principalmente, no labro onde também é mais densa.
Inteiramente coberta pela pilosidade no vértice e no mesossoma, fina e esparsa nos flancos do propódeo, e muito fina e pilígera, nos tergos.

Estrutura e proporções. O clípeo complemente abaulado; labro subtrapezoidal com os cantos arredondados; carena frontal aberta em fenda estreita no terço superior terminando em frente ao ocelo, a uma distância equivalente a um diâmetro do ocelo. Os palpos maxilares com 4 artículos, sendo o $1^{\circ}$ um pouco mais engrossado e o $4^{\circ}$ bem mais curto que os demais; placa pigidial dupla, a superior reticulada, curta e larga, e a inferior deprimida dos lados para o meio e elevada na metade apical, terminando em ponta (Fig. 4); placa basitibial simples, côncava, elevada na base, com desenho amarelo imitando uma placa, a mancha amarela da base para o centro, ultrapassando a elevação basal, sendo esta de um amarelo um pouco mais escuro (Fig. 2). As mandíbulas com 4 dentes normais e um dentículo basal, os dentes rombudos, com exceção da extremidade apical do dente apical.

O comprimento do escapo menor que a distância alveolocelar lateral; a distância clípeo-ocelar aproximadamente 4/5 do comprimento do clípeo; clípeo e labro mais largos que longos; gena, de perfil, aproximadamente duas vezes e meia mais estreita que a largura do olho.

Mensurações: comprimento e largura do olho 2,976:1,643; largura da gena e do olho de perfil 0,48:1,056; distâncias interorbitais superior, média e inferior 2,418:2,511:2,201; comprimento e largura do clípeo 1,271:1,953; distâncias clípeocelar, interalveolar, alveolorbital, alveolocelar, ocelorbital, interocelar 1,085:0,84:0,496:0,899:0,48:0,24; diâmetro do alvéolo 0,24; comprimento e diâmetro do escapo 0,696:0,288; diâmetro do ocelo médio 0,336; comprimento e largura do labro 0,744:1,296; comprimento e largura da placa basitibial 1,032:0,576.

Alótipo macho. Comprimento total aproximado 10,1; comprimento da asa anterior 8,4 ; largura máxima da cabeça 4,5 ; largura do metassoma na altura de T2 4,7.

Muito semelhante à fêmea, diferindo desta nos seguintes caracteres: clípeo sem as manchas castanho-escuras do terço superior (Fig. 5); estria paraocular terminando na altura da tangente inferior dos alvéolos, a maior largura situada acima das fóveas tentoriais, e o estreitamento apical bastante curto; escapo amarelo ventralmente; reflexo azul-lilás-metálico muito forte, ocupando toda a extensão dos tergos 4 e 5 , e pequenas manchas arredondadas laterais, próximas às faixas brancocerdosas, nos tergos 2 e 3 , e por baixo dos pêlos plumosos no $1^{\circ}$ tergo; mesossoma, incluindo apenas as coxas, castanhoenegrecido com um leve brilho esverdeado-metálico (verde musgo), porém, bem menos brilhante que o metassoma; fêmures posteriores castanho-laros, com exceção da margem dorsal e da extremidade apical, ferrugíneas; como na fêmea, base das tíbias com mancha amarela.

No geral, a pilosidade bastante semelhante à da fêmea, porém mais densa e longa no $1^{\circ}$ tergo, cobrindo o tergo por completo, este sem as microcerdas castanhas da parte central; as faixas de cerdas esbranquiçadas dos bordos apicais do $2^{\circ}$ ao $5^{\circ}$ tergo mais alargadas, as cerdas mais espessas e densas 

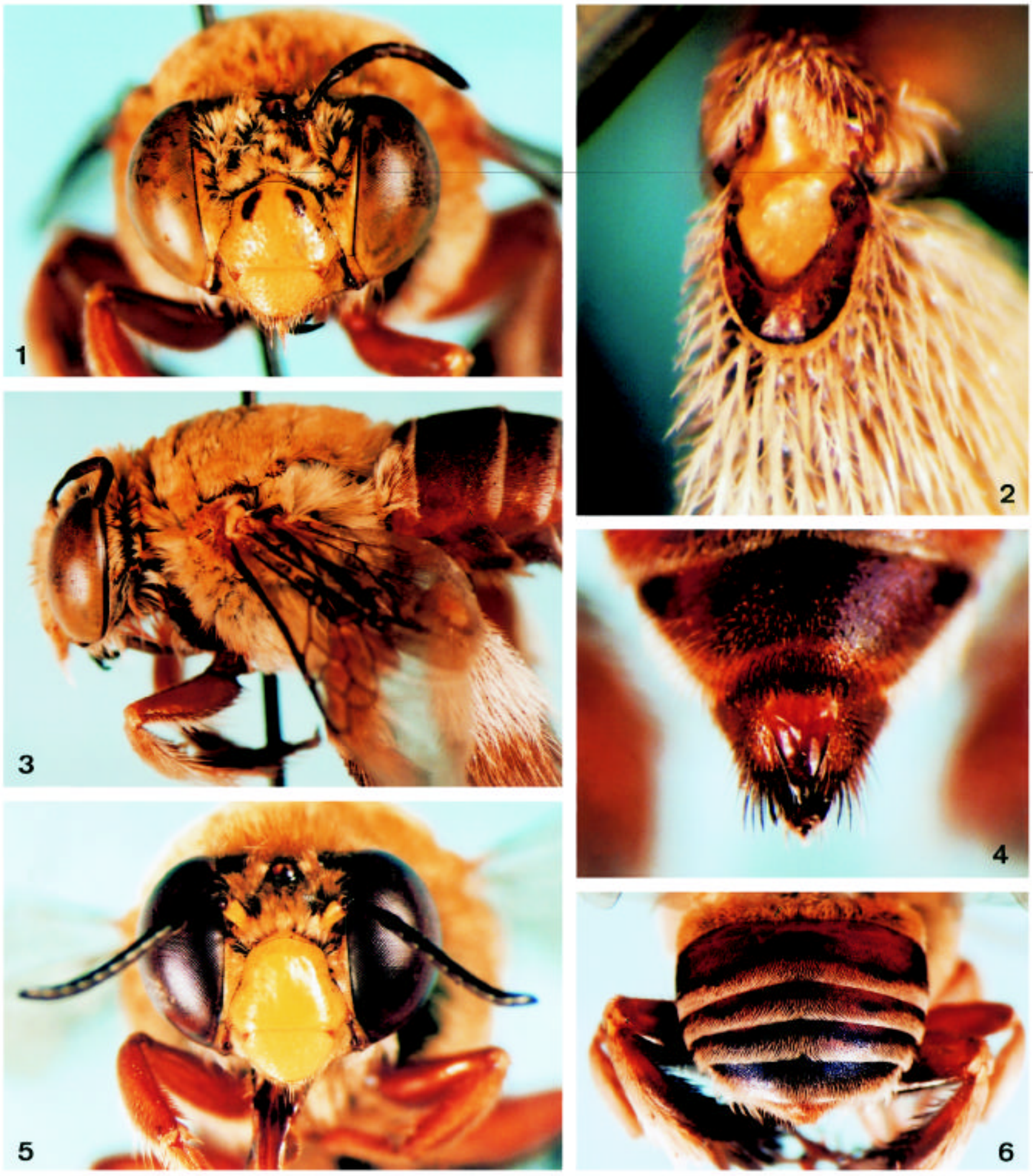

Figs. 1-6. Centris pulchra sp. nov. 1-4, Holótipo fêmea: 1, vista frontal da cabeça; 2, placa basitibial; 3, mesossoma de perfil; 4, placa pigidial; 5-6, Alótipo macho: 5, vista frontal da cabeça; 6, vista dorsal do metassoma. 
(Fig. 6); nas pernas posteriores, os pêlos plumosos acastanhados, exceto os da extremidade apical dos fêmures e os da metade posterior da face dorsal das tíbias, estes esbranquiçados; pêlos dos esternos com aparência uniforme. Pilosidade bastante desenvolvida nos gonóstilos.

A pontuação do macho é praticamente igual à da fêmea, porém a parte média do clípeo é mais lisa, com pontos esparsos para os lados, adensados nos declives laterais.

Estrutura e proporções. Difere da fêmea nos seguintes aspectos: labro mais arredondado na extremidade apical; mandíbula tridentada, com 1 dentículo basal, sendo o $1^{\circ}$ dente pontiagudo e os demais truncados. Todas as pernas inermes. O comprimento do escapo aproximadamente $3 / 4$ da distância alveolocelar lateral $(0,63: 0,8)$. Clípeo e labro mais largos que longos; a distância clípeo-ocelar aproximadamente $2 / 3$ do comprimento do clípeo. A largura da gena, de perfil, aproximadamente duas vezes e meia mais estreita que a largura do olho $(0,496: 1,302)$.

Mensurações: comprimento e largura do olho 2,976:1,736; distâncias interorbitais superior, média e inferior 2,108:1,891:2,015; comprimento e largura do clípeo 1,426:1,891; distâncias clípeo-ocelar, interalveolar, alveolorbital, alveolocelar, ocelorbital, interocelar 0,992:0,775:0,24:0,32:0,31:0,248; diâmetro do alvéolo 0,403; comprimento e diâmetro do escapo 0,31:0,682; diâmetro do ocelo médio 0,372 ; comprimento e largura do labro 0,806:1,488.

Material-tipo. Todos os exemplares foram coletados em BRASIL, Bahia: Salvador, Abaeté, por B.F. Viana: Holótipo fêmea (em 01/IX/96 às 08:25 horas, em Waltheria cinerescens St. Hil (n. $\left.{ }^{\circ} 22\right)$,) e alótipo (14/ X/96, 9:55 hs, em Cuphea branchiata Koehne (n. $\left.{ }^{\circ} 3\right)$ ), depositados na Coleção de Entomologia Pe. J.S. Moure, da Universidade Federal do Paraná, Curitiba, Brasil (DZUP). Parátipos: 24 fêmeas (05/III/1996, 07:25 hs; 04/X/1996, 07:50 hs; 01/IX/1996, 08:30 hs; 24/VIII/1996,
11:40 hs; 12/VIII/1996, 14:15 hs; 14/X/1996, 08:30 hs; 01/IX/1996, 08:30 hs; 19/I/1996, 08:10 hs; 14/X/1996, 08:15 hs - em Krameria bahiana B.B. Simpson ( $\left.{ }^{\circ} 16\right) /$ 01/IX/1996, 10:20 hs; 01/X/1996, 12:20 hs - em Eriope blanchetii (Benth) Harley (n $\left.{ }^{\circ} 10\right) / 26 / \mathrm{X} / 1996,11: 35$ hs - em Chamaecrista ramosa (Vog.) I \& B var. ramosa / 14/III/1996, 9:05 hs; 14/III/1996, 10:20 hs; 05/XI/1996, 9:15 hs - em Cuphea brachiata Koehne ( $\mathrm{n}^{\circ}$ 3) / 05/XI/1996, 11:15 hs - em Byrsonima teopteridifolia Juss $\left(\mathrm{n}^{\circ}\right.$ 1) / 11/IX/1996, 13:45 hs - em Ouratea rotundifolia (Gardn.) Engl. ( $\mathrm{n}^{\circ}$ 45) / 11/IX/1996, 8:10 hs; 03/VIII/1996, 12:10 hs; 01/IX/ 1996, 12:25 hs; 11/IX/1996, 11:00 hs - em Stylosanthes viscosa $\mathrm{Sw}\left(\mathrm{n}^{\circ}\right.$ 46) / 01/IX/1996, 7:40 hs; 11/IX/1996, 7:40 hs; 11/IX/1996, 13:35 hs em Waltheria cinerescens St. Hil (n. $\left.\left.{ }^{\circ} 22\right)\right)$ e 6 machos (13/V/1996, 12:00 hs; 13/V/1996, 14:20 hs; 04/X/1996, 14:50 hs; 15/XI/1996, 12:55 hs; 05/XI/1996, 13:05 hs - em Cuphea branchiata Koehne (n. ${ }^{\circ}$ 3) / 14/X/ 1996, 14:00 hs - em Krameria bahiana B. B. Simpson ( $\left.\mathrm{n}^{\circ} 16\right)$ ), depositados na coleção do Laboratório de Biologia e Ecologia de Abelhas (LABEA), Departamento de Zoologia, Instituto de Biologia, Universidade federal da Bahia, Salvador, Bahia, Brasil.

\section{REFERÊNCIAS}

Pinheiro-Machado, C.; I. Alves-Dos-Santos; V. L. Imperatriz-Fonseca; A. M. P. Kleinert \& F. A. Silveira. 2002. Brazilian bee surveys: state of knowledge, conservation and sustainable use, p. 115-130. In: P. G. Kevan \& V. L. Imperatriz-Fonseca (eds.). Pollinating bees: the conservation link between agriculture and nature. Brasília, Ministério do Meio Ambiente, 313 p.

Sakagami, S. F; S. Laroca \& J. S. Moure. 1967. Wild Bee Biocenotics in São José dos Pinhais (PR), South Brazil. Journal of Faculty of Science of Hokkaido, University VI, Zoology 19: 180-250.

Silveira, F. A.; C. Pinheiro-Machado; I. Alves-Dos-Santos; A. M. P. Kleinert \& V. L. Imperatriz-Fonseca. 2002. Taxonomic constraints for the conservation and sustainable use of wild pollinators - the Brazilian wild bees, p. 41-50. In: P. G. KeVAn \& V. L. Imperatriz-Fonseca (eds.). Pollinating bees: the conservation link between agriculture and nature. Brasília, Ministério do Meio Ambiente, 313 p. 